\title{
Quality assurance system as on object of comparative research
}

\author{
Alfia Gazizova ${ }^{1 \mathrm{a}}$ \\ ${ }^{1}$ Kazan Federal University, Naberezhnye Chelny Institute, Naberezhnye Chelny, Mira pr. 68/19, \\ 423810, Russia
}

\begin{abstract}
Ongoing processes of globalization and acceleration of world development rates cause, by necessity, the studying of foreign experiences in different spheres of public life, including development of Higher Education (HE). The author concentrates attention to study and analysis of HE development of Turkey, vis-à-vis Russia and European countries, examines features of Quality Assurance (QA) system development, singling out new ideas and constructive strategies. Directions of improving academic staff professionalism based on increase of scientific, pedagogical (methodical) qualification, language competence development are presented that is of interest for academia in light of current Russian academic system changes according to integration into international structures.
\end{abstract}

\section{Introduction}

Turkey (as well as Russia and European countries) shares an orientation towards the increase of national competitiveness and the creation of an innovative society; is under strong influence of world integration tendencies; and, is characterized by its seeking of an optimal balance between its developed traditions and the principles of the Bologna reforms. Proceeding from our analysis of HE problem zones in Russia, we have examined the peculiarities of HE development in Turkey, revealing perspective directions.

One of the most important strategy has been expressed in the Turkish experience by the development of new directions in Quality Assurance (QA), such as: the promotion of internal quality assurance systems that are made more effective according to world experience; the active attraction of international experts and students to an external assessment of an institution's professional activities and academic programs; the use of international standards in areas including Bachelor's and Master's qualification descriptors, etc. These QA assessments strengthen Turkey's integration into overall European structures and thus promote the multi-dimensional preparation of teachers for professional work in the field [1].

\footnotetext{
${ }^{a}$ Corresponding author: author@e-mail.org
} 


\section{Quality assurance system}

The Turkish QA model differs in essential respects from Russian traditions in higher education management, being concerned as it is with certification regimes according to ISO 9000 standards, Total Quality Management (TQM), principles of international academic and professional accreditation organizations focused on carrying out the internal analysis and quality assessment on the basis of set standards. Adoption of such a self-assessment culture makes each higher educational institution responsible for the quality of its various activities that finds economic support in many developed countries.

\subsection{Russian experience}

The National system of QA in Russia developed in the 1990s has also expressed via its restructuring, on the one hand, the state interest to follow the European academic standards (e.g. in the development of internal, institutional QA system), yet, on the other hand, is still dominated by an external state evaluation of educational process quality that constrains the rise of a quality culture in specific Russian institutions. Even so, one can already observe an active development of a new QA systems in Russia: 1860 HEIs and their branches have established inner quality assurance systems [2]. There is a tendency towards certification of quality systems and accreditation of academic programs by foreign QA. As for the international cooperation in the area, in Russia is represented in international networks and associations of quality assurance agencies (INQAAHE, ENQA, CEENGT, EAQAN, APQN, IAEA).

The provision of a unified educational area in Russia through the federal state educational standards, systems of licensing and accreditation (institutes, academic programs) has appeared, nonetheless, to be quite effective. At the same time, the model employed differs from the Turkish one as the Ministry of Education and Science simultaneously performs the roles of graduate customer, organizer and executor of training, and also as the QA control body (through federal state executive body - Federal Service of Supervision in Education and Science (Rosobnadzor). This is a national peculiarity of Russian educational system that does not contradict the principles of the Bologna Declaration. However, it contradicts the needs of the developing economy in that it does not reflect branch principles of professional training management. In that case, it is useful to refer to the positive experience of Turkey in providing external assessment of programs by independent agencies based on the established criteria and developing competencies in academic standards.

\subsection{French experience}

It is also fruitful to refer French principle of regular assessing the quality of higher education by Independent Administrative authority - The Agency for the evaluation of research and higher education (AERES). Furthermore, there are two specialized Commissions, the one for engineering programmes, and the other one for management programmes are responsible for the external quality assessment of institutions, programmes and research activities. These three bodies are undertaking their assessments, freely and away from any pressure or subordination.

The outcomes of an external assessment made by the AERES Agency are taken on board when the ministry for HE and Research (MHER) and the university are having a dialogue with each other, before any 5-year agreement is signed. These outcomes are the basis for any accreditation decision taken by the MHER about a national HE degree, with the allocation of financial resources and human resources that goes with it [3]. 
The recent set up of the AERES (2006) in France is understood as a major development in the wake of the French policy for modernizing higher education and research and the reforms. On the other hand, it reflects the desire of the Government of France to create a common mechanism for assessing the quality of higher education institutions at the national level, since the first assessment mission of educational institutions, research units and institutions entrusted to a single structure. In addition, it gives an opportunity to form a tool for assessing the quality of higher education institutions and research organizations.

Recent advances in HE and research area in France shows that the state performs functions rather of strategic management than direct management that is more characteristic for Russia. Turkey also aims to establish independent national external QA system in accordance with European guidelines. Processes of institutional and specialized accreditation conducted by independent and international accreditation agencies are considered to be progressive forms of self-regulation.

\subsection{Academic staff professionalism in Turkey}

Our study of Turkish experience has shown that the quality assurance system is closely linked with the level of teaching staff professionalism. Versatile professional training of teachers orientated to the increase of scientific, pedagogical (methodical) qualification, language competence reflects their integration into the international academic environment where specific infrastructural skills of teaching, research activity are claimed (economic, scientific, social, linguistic skills for carrying out joint scientific projects) [4].

Directions of improving academic staff professionalism in Turkey are the following:

a) Scientific qualification increase:

- Sending doctorate students aboard (including projects such as «semester in foreign universities»)

- Creation of integrated doctorate programs with foreign universities

- Sending research assistants from developing to developed universities for their doctorate studies

- Opening new doctorate programs and entrance of university graduates to academic and research positions

b) Pedagogical (methodical) qualification development:

- Organization of short-term courses on planning of training process and assessment of its results (within PH.D programs)

- Organization of refresher courses by means of Internet resources

- Mentoring ("master-learner" model)

- Self-education (supervision over teaching process of skilled colleagues)

c) Change of entrance, academic promotion and certification conditions:

- Introduction of minimum requirement for an academic position (Ph.D degree)

- Primary attention to research activity in subject domain

- Peer-reviewed publications in scientific journals

- Assessment of teaching activity in HEIs (report on work, students poll, working of new courses, international activity)

d) Language competence development:

- Introduction of high requirements to language proficiency (working up programs, conducting classes in foreign language, passing qualification examination)

- Introduction of testing for foreign language knowledge

- Writing articles

All realized directions are worthy in Russia because of specific problems (aging of academic staff, reduction of faculty conducting research, low level of universities in the 
world scientific rates, low level of the academic mobility, etc.) and HE integration into the international educational space. Rigid requirements to the qualification of teachers (Ph.D) in Turkey reflects high status of scientific research, establishing direct dependence of academic career on research productivity is definitely a factor of enhancing motivation towards scientific research development. Foreign language proficiency is historically a subject of serious attention of Turkish government and academic circles and is realized through: developing English-speaking HE, including two state universities and a private one with English-training system; developing and active introducing of academic programs, communication- focused and professionally-oriented courses in English; executing doctoral researches according to world tendencies; offering courses in less spread languages within international programs.

\section{Summary}

In the overall the strategy of improving teachers' professional activity in Turkey is focused on strengthening of state research potential and international partnership in scienceeducation spheres, and it is obvious HEIs are the major research organizations in the country.

Russia pursues similar aims, assumes receiving profit from realization of scienceeducation-production interaction. Restructure of HE sector in Russia through singling out of federal and national research universities, its reforming in light of European integration creates favorable prerequisites for the transition of high school to a qualitatively new model, related to strengthening of universities' position in the field of global academic ratings and developing state scientific and innovative complex as a whole (emphasis on publications growth in reviewed editions and $\mathrm{HE}$ sector financing). But the lack of language proficiency and international contacts remain the obstacles to greater involvement of academic staff in significant projects.

Constructive ideas and approaches from Turkey's experience, in our opinion, are connected with enhancing international cooperation in all academic and scientific areas: academic mobility (participation in scientific and educational projects of foreign universities and organizations, development of practical study, grant and scholarship programs, etc.), strengthening of linguistic (English) education including partnership with foreign colleagues in training courses for innovative activity. Experience of international cooperation in QA, development of joint programs at all levels, versatile training of teaching staff, that contribute to effective integration of state into the international structures are of special interest for many countries.

\section{References}

1. Gazizova A. (2012). From Turkey to Russia with love: a comparative study of higher education policy strategies in light of ongoing reforms, European Journal of Higher Education, Vol.2, Nos 2-3 (June-September), pp.198-204.

2. Arzhanova I.V., Blinov V., Gevorkyan E., Zhurakovsky V., Karpukhina E., et el. (2009). Bologna Process National Reports 2007 - 2009: Russian Federation. http://www.ond.vlaanderen.be/hogeronderwijs/bologna/links/National-reports2009/National_Report_Russia_2009.pdf

3. National Report regarding the Bologna Process implementation 2009-2012 : France (2012).http://www.ehea.info/Uploads/National\%20reports/France\%20Rep\%20and\%20 Annex.pdf 
4. Gazizova A. (2013). Foreign experiences in light of higher education reforms. In 2013 International Conference on Interactive Collaborative Learning 